\title{
Multimarket Contact and Pricing: A Case of the U.S. Airline Industry
}

\author{
W.F GUO \\ Xiamen University, Fujian, China
}

\begin{abstract}
Focusing on the case of JetBlue, our study of JetBlue's main markets with 4122 sample observations empirically investigates the effects of multimarket contacts (MMC) on U.S. air carriers' pricing behaviors of low-cost carriers (LCCs) and full-service carriers (FSCs) as well as those among LCCs. We estimate the simultaneous demand and price (pseudo-supply) equations to derive these impacts of MMC and find: (1) the effect of multimarket contacts is lowered when FSCs compete with LCCs; (2) LCCs' airfares stay at low levels, even though they repeat multimarket contacts among LCCs. The analysis results reveal that the JetBlue's behaviors have strong impacts on lowering airfares.
\end{abstract}

KEYWORD: MMC; pricing; LCC; JetBlue

\section{INTRODUCTION}

Multimarket competition is defined as 'a situation where firms compete with each other simultaneously in several markets' (Karnani and Wernerfelt, 1985).The major focus of multimarket contact research has been directed towards the investigation of the 'mutual forbearance' hypothesis. This hypothesis suggests that as the number of multimarket contacts between a pair of firms increase, the intensity of rivalry between these firms across markets decrease. Murakami (2011b) studied whether price-lowing effects due to LCC entries lasted over time and estimated the change in social welfare in accordance with the change in airfares of full-service carriers (FSCs) and LCCs. However, few previous studies have applied the idea of the competitive effect of multimarket contact to examining airline competitions with LCCs especially JetBlue Airway, who rapidly grew to become the second largest LCC in the U.S. airline industry and draw attentions for the interesting combination of implementing its low-cost and differentiation strategy.

\section{ECONOMETRIC MODEL}

We follow the methods of simultaneous demand and pseudo-supply equation system (Dresner et al. (1996) and Murakami \& Asahi (2011a, 2011b)) by nonlinear 3SLS (three stage least squares) proposed by Jans and Rosenbaum (1997), to estimate and measure the effect of multimarket contact. We add a multimarket contact variable and the case with JetBlue dummy to the right-hand side of the pseudo-supply equation as follows:

\section{[Demand equation]}

$$
\begin{aligned}
\log Q_{k j}= & \alpha_{0}+\alpha_{1} \log P_{k j}+\alpha_{2} \log D I S T_{j}+\alpha_{3} \log I N C_{j} \\
& +\alpha_{4} \log P O P_{j}+u_{k j}
\end{aligned}
$$

\section{[Pseudo-supply equation]}

$$
\begin{aligned}
\log P_{k j}= & \beta_{0}+\beta_{1} \log Q_{k j}+\beta_{2} \log D I S T_{j}+\beta_{3} \log H H I_{j} \\
& +\beta_{4} L C C_{k j}+\beta_{5} V S L C C_{k j}+\left(\beta_{6}+\theta_{1} B 61+\theta_{2} B 6 R 1\right. \\
& \left.+\theta_{3} B 62+\theta_{4} B 6 R 2\right) \log M M C_{k j}+e_{k j}
\end{aligned}
$$

The description of the variable of the model is shown as table 1.Dist $j_{j}$ in the pseudo-supply equation is used as the proxy variable of marginal cost. It has been widely accepted that airline operations are characterized by economics of distance. Distance is the major variable that affects costs. This variable will have a positive effect on airfares. To control for the impact of market concentration on airfare, we use the Herfindahl index- $-\mathrm{HHI}_{\mathrm{j}}$ and a higher $\mathrm{HHI}_{\mathrm{j}}$ means that the market is more concentrated. Since high concentration may lead to strong market power, the parameter will be positive. $\mathrm{MMC}_{\mathrm{kj}}$ measures the degree of carrier k's multimarket contact on route $\mathrm{j}$. The sign of this parameter will be positive if multimarket contact has collusive effect. Bailey et al. (1985) suggested that market concentration is an endogenous variable determined by output, variable of multimarket 
contact may be endogenous. As a pilot study, we suppose that $\mathrm{HHI}_{\mathrm{j}}$ and output are endogenous variables. Here, $\mathrm{u}_{\mathrm{kj}}$ and $\mathrm{e}_{\mathrm{kj}}$ are random error terms of the demand equation and pseudo-supply equation, respectively.

In order to determine whether the airfare level of JetBlue differed between primary and secondary airports, we introduce the dummy variables B61, B62, B6R1, and B6R2. B61 take 1for JetBlue operating in the primary airport, and B6R1 takes 1 for the FSCs that are competing with JetBlue at the primary airport. Similarly, B62 takes 1 for JetBlue operating in the secondary airport, and B6R2 takes 1 for FSCs that are remotely competing with JetBlue at the secondary airport.

\section{[Multimarket contact (MMC) measurement]}

There are several different ways to measure multimarket contact. The most commonly used approach is to count the number of overlapping markets in which firms compete with one another. In the context of the airline industry, the count of overlapping routes served by airlines is widely used to measure the extent of multimarket contact between carriers (for example, Evans \& Kessides (1994); Gimeno \& Woo (1999); and Baum\& Korn(1999)). Building on this measurement, two steps were followed. First, we counted the number of contacts between any pair of carriers $i$ and $j$ across all routes as $\mathrm{a}_{\mathrm{kl}}$ :

$$
a_{k l}=\sum_{j=1}^{n} D_{k j} D_{l j}
$$

where $D_{k 1}$ is a dummy variable that equals 1 if airline $i$ flies on route $r$, and 0 otherwise.

Then, the multimarket contact $\mathrm{MMC}_{\mathrm{kj}}$ between airlines $i$ and $j$, denoted as $f_{j}$ which is the number of carriers on the route $j$, was scaled by the sum of the number of routes that each carrier flies. From the matrix, the airline multimarket contact for route jcan is constructed:

The formula for $\mathrm{MMC}_{\mathrm{kj}}$ is:

$$
M M C_{k j}=\frac{\sum_{k \neq l} a_{k l} D_{k j} D_{l j}}{f_{j}-1}
$$

\section{THE DATA}

We use the cross-sectional data of the year 2006, comprised of $10 \%$ samples of U.S. domestic flight data collected from DB1A, which are scheduled operations by city-pair route by firm. Following the data-filtering approach by Murakami (2003,2011b), we excluded carriers that did not have $10 \%$ market share in duopoly markets and those that did not have $5 \%$ share in triopoly or greater markets. The routes which passengers were less than 5000/year (14/day) were omitted. The samples considered in our analysis are 10 U.S. airports which are JetBlue base or hub airports: New York/Newark area (JFK, LaGuardia (LGA), Newark (EWR)), Washington D.C. area (National, Dulles, Baltimore), Orlando (MCO), Oakland (OAK), Fort Lauderdale (FLL), and Boston (BOS). Our database consists of 581 duopoly markets, 399 triopoly markets, 500 fourcarrier-operating markets, 98 five-carrier-operating markets, 28 six-carrier-operating markets, 10 sevencarrier-operating markets, 1 eight-carrier-operating market and 2 nine-carrier-operating markets. Our dataset contains the routes where FSCs compete with each other as well as the route where LCCs and FSCs compete. The final sample has 4112 observations and includes 12 carriers.

Following the idea of Murakami and Asahi (2011), we classify the sampled nineteen carriers into FSCs and LCCs, and define AirTran Airways, JetBlue Airways, Frontier Airlines, and Southwest Airlines as LCCs.

\section{EMPIRICAL RESULTS}

Table 2 presents the results of measuring the effect of multimarket contact under both cases: estimated parameters without coefficient binary variables of price equation, and the case of JetBlue (the right column).

The empirical results for both cases show that the coefficient of multimarket contact is significantly positive. Both of them show that multimarket contact has a collusive effect. These results are consistent with previous studies that suggest multimarket contact has led to collusive establishment of high airfares in the airline industry.

We also introduce the JetBlue's dummy variable to determine whether the airfare level of JetBlue differed between primary and secondary airports due to multimarket contact. B61 take 1 for JetBlue operating in the primary airport, and B6R1 takes 1 for the FSCs that are competing with JetBlue at the primary airport. Similarly, B62 takes 1 for JetBlue operating in the secondary airport, and B6R2 takes 1 for FSCs that are remotely competing with JetBlue at the secondary airport. The results tell us that JetBlue's low-airfare strategy at the primary airports led to low airfares, and the same was true in the secondary airports. The coefficients of B6R1 and B6R2 are significantly negative. This result suggests that FSCs also lowered their airfares to cope with the competition from JetBlue. We reject the hypothesis that $\theta_{4}=\theta_{3}$ by the Wald test, and

$\chi^{2}=24.37$ with degree of freedom (d.o.f) $=1$, Pvalue $=0.000$. The result suggests the JetBlue's impact is different between the primary airports and the secondary airports. The influence of multimarket contact on FSCs' pricing behavior is 
also related to the market power of JetBlue and different from the primary airports and the secondary airports. The empirical results indicate that the parameters of variables meet the expected signs and are statistically significant, except for the case of the B61and B62 in the price equation with binary variables. The parameter of B61 and B62 are not significantly negative. The reason is that JetBlue has entered long-haul markets and provided small frills and airfares that do not much differ from those of FSCs in certain routes, especially at the secondary airports where JetBlue chose to base in order to eschew the hub-and-spoke architecture of FSCs.

\section{DISCUSSION}

Summarizing the findings of the empirical analyses, LCCs' airfares stay at low levels, even though they repeat multimarket contacts among LCCs. These results suggest that JetBlue's behaviors are not affected by multimarket contacts, and that these behaviors have strong impacts on lowering airfares on both primary airports and secondary airports.

Table 1 Descriptive variable

\begin{tabular}{|l|l|}
\hline Variable & Description \\
\hline$P_{k j}$ & The average airfare of route $\mathrm{j}$ of carrier $\mathrm{k}$. \\
\hline$Q_{k j}$ & The average output of route $\mathrm{j}$ of carrier $\mathrm{k}$. \\
\hline$P O P_{j}$ & The arithmetic average of the $\mathrm{O} / \mathrm{D}$ (origin/destination) population. \\
\hline$I N C_{j}$ & The arithmetic per-capita income of route $\mathrm{j}$. \\
\hline$D I S T_{j}$ & The distance between a city pair of route $\mathrm{j}$. In the pseudo-supply equation is used as the proxy variable of marginal cost. \\
\hline$M K T_{j}^{m}$ & The variable is to control the market size in the demand equation. \\
\hline$H H I_{j}$ & $\begin{array}{l}\text { The sum of squared market shares of all carriers flying on route } \mathrm{j} \text {. Since the high concentration may lead to strong } \\
\text { market power, the parameter will be positive. }\end{array}$ \\
\hline$L C C_{k}$ & A binary variable that takes 1 if carrier $\mathrm{k}$ is an LCC. \\
\hline$V S L C C_{k j}$ & A binary variable that takes 1 if carrier $\mathrm{k}$ competes with LCC(s) in a market. \\
\hline$B 61$ & A binary variable that takes 1 for JetBlue operating at the primary airport and 0 otherwise. \\
\hline$B 6 R 1$ & A binary variable that takes 1 for the FSCs that are competing with JetBlue at the primary airport and 0 otherwise. \\
\hline$B 62$ & A binary variable that takes 1 for JetBlue operating at the secondary airport and 0 otherwise. \\
\hline$B 6 R 2$ & $\begin{array}{l}\text { A binary variable that takes } 1 \text { for FSCs that are remotely competing with JetBlue at the secondary airport and } 0 \\
\text { otherwise. }\end{array}$ \\
\hline$M M C_{j}$ & The carrier k's multimarket contact on route j. \\
\hline
\end{tabular}

Table 2 Estimated Results

\begin{tabular}{|c|c|c|c|c|c|c|}
\hline \multirow{2}{*}{ Variable } & \multicolumn{3}{|l|}{ Model } & \multicolumn{3}{|c|}{ Case of JetBlue } \\
\hline & Parameter & Standard error & p-Value & Parameter & Standard error & p-Value \\
\hline \multicolumn{7}{|c|}{ Demand equation } \\
\hline Airfare & -2.8020 & 0.2074 & 0.0000 & -2.7043 & 0.2040 & 0.0000 \\
\hline Distance & 1.3544 & 0.1617 & 0.0000 & 1.3071 & 0.1603 & 0.0000 \\
\hline Population & 0.2327 & 0.0385 & 0.0000 & 0.2300 & 0.0383 & 0.0000 \\
\hline Income & -0.9332 & 0.2549 & 0.0000 & -0.9179 & 0.2539 & 0.0000 \\
\hline Constant & 15.9688 & 2.7094 & 0.0000 & 15.6834 & 2.6996 & 0.0000 \\
\hline \multicolumn{7}{|c|}{ Pseudo-supply equation } \\
\hline Output & 0.0364 & 0.0276 & 0.1860 & 0.0346 & 0.0230 & 0.1320 \\
\hline HHI & 0.0809 & 0.0184 & 0.0000 & 0.0955 & 0.0186 & 0.0000 \\
\hline Distance & 0.5159 & 0.0218 & 0.0000 & 0.5231 & 0.0217 & 0.0000 \\
\hline LCC & -0.1546 & 0.0225 & 0.0000 & -0.1960 & 0.0254 & 0.0000 \\
\hline VSLCC & -0.2692 & 0.0291 & 0.0000 & -0.2657 & 0.0251 & 0.0000 \\
\hline $\operatorname{MMC}(\beta 6)$ & 0.0187 & 0.0088 & 0.0340 & 0.0326 & 0.0096 & 0.0010 \\
\hline B61( $(\theta 1)$ & & & & -0.0244 & 0.0173 & 0.1600 \\
\hline $\operatorname{B6R1}\left(\theta_{2}\right)$ & & & & -0.0185 & 0.0045 & 0.0000 \\
\hline B62 $\left(\theta_{3}\right)$ & & & & -0.0211 & 0.0521 & 0.6850 \\
\hline B6R2 $\left(\theta_{4}\right)$ & & & & -0.0270 & 0.0055 & 0.0000 \\
\hline Constant & 1.0149 & 0.2193 & 0.0000 & 0.9322 & 0.2139 & 0.0000 \\
\hline
\end{tabular}




\section{REFERENCES}

[1] Bernheim, B.D., and Whinston. 1990. Multimarket contact and collusive behavior.The RAND Journal of Economics, 21 (1), 1-26.

[2] Evans, W.N., and I.N. Kessides.1994.Living by the 'Golden Rule': multimarket contact in the US airline industry.The Quarterly Journal of Economics, 109 (2), 341-366.

[3] Fernandez, N., and P.L. Marin. 1998 .Market power and multimarket contact: some evidence from the Spanish hotel industry. The Journal of Industrial Economics.46 (3), 301315.

[4] Jans,I., and Rosenbaum,D.I.1997. Multimarket contact and pricing: evidence from the U.S. cement industry. International Journal of Industrial Organization, 15(3) 391412.

[5] Karnani,A andWernerfelt,B. 1985. Multiple point competition.Strategic Management Journal,Volume 6, Issue 1, 87-96.
[6] Kim,E.H., and Singal,V.1993. Mergers and market power: evidence from the airline Industry. American Economic Review, 83, 549-569.

[7] Murakami,H., and Asahi,R.2011. Market power and multimarket contact: a case of the U.S. airline industry. Hitotsubashi Journal of Commerce and Management 45, 81-88.

[8] Murakami, H., 2011, a.Empirical analysis of inter-firm rivalry between Japanese full-service and low-cost carriers. Pacific Economic ReviewVolume 16, Issue 1, 103-119.

[9] Murakami, H. 2011, b. Time effect of low-cost carrier entry and social welfare in U.S. large air markets. Transportation Research Part E, 47,306-314.

[10]Oum, T. H., A. Zhang and Y. Zhang. 1993.Inter-Firm Rivalry and Firm-Specific Price Elasticitiesin the Deregulated Airline Markets, Journal of Transport Economics and Policy, 27, 171-92.

[11]Zou, L., M. Dresner, and R.J. Windle. 2011. Many fields of battle: how cost structure affectscompetition across multiple markets. Journal of Transport Economics and Policy, 45 (1), 21-40. 